Dept of Animal Diseases,

Faculty of Veterinary Medicine, Al Baath Univ.

\title{
STUDY ON BLOOD BIOCHEMICAL VALUES ON PREGNANCY TOXEMIA IN SYRIAN AWASI EWES
}

(With 3 Tables and 10 Figures)

\author{
By

\section{KABAWI; N. DABBAGH* and A. DAKKA} \\ * Dept. of Path. Physiology, Fac. of Vet. Med., Al Baath Univ.
}

(Received at 3/4/2010)

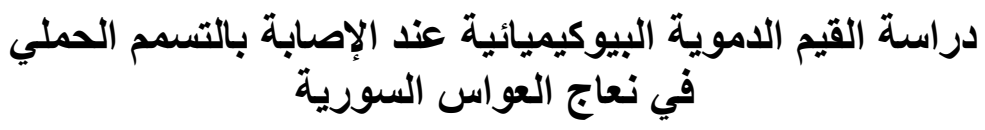

\section{محد قباوي ، نادر دباغ ، عدنان الدقة}

أجري البحث على 103 رؤوس من النعاج العواس العشار في البادية السورية خلال شهري

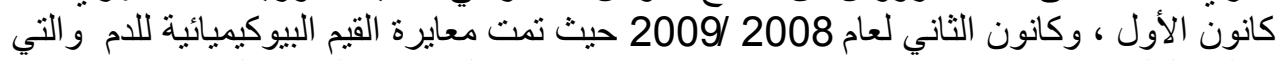

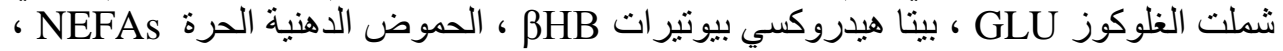

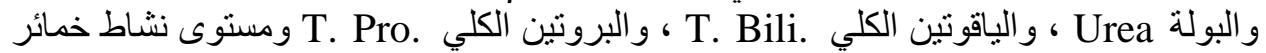
ALT ، AST

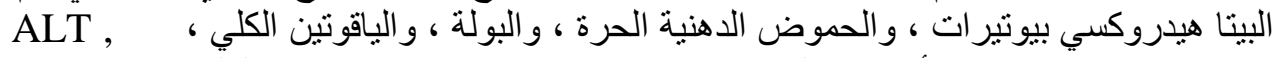

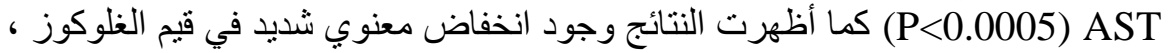

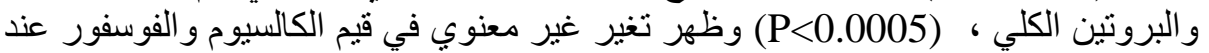
النعاج المصابة مقارنة مع النعاج الثـاهد.

\section{SUMMARY}

This study was carried out on 103 heads of pregnant Awasi sheep during the months of December and January of 2008/2009. The concentrations of Glucose, $\beta$ - Hydroxy biotyrate ( $\beta \mathrm{HB}$ ), Non esterified fatty acids (NEFAs), Urea, Total Bilirubin, Total Protein, Alanine aminotransferase (ALT), Aspartate aminotransferase (AST), Ca, P, were all tested. It was shown from the results that there was significant increase of $\beta \mathrm{HB}$, NEFAs, Urea, T. Bili., AST, and ALT. There was significant decrease of Glucose, T. Protein in blood serum (value of $\mathrm{P}<0.0005$ ) but there was insignificant changes in $\mathrm{Ca}, \mathrm{P}$ value between control and affected animals. These results were discussed in the shadow of previous related studies.

Key words: النعاج، التسمم الحملى ، قيم الدم البيوكيميائية 


\section{INTRODUCTION المقدمـة}

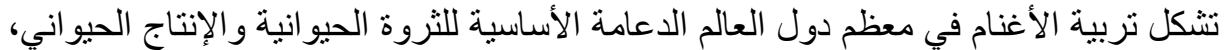

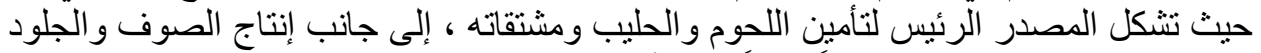

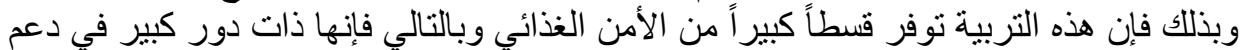

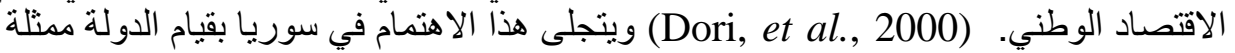

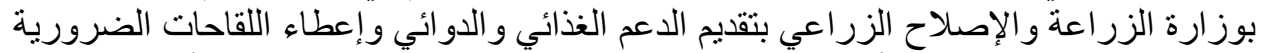

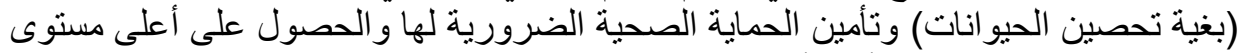

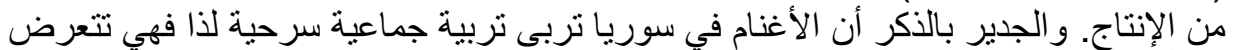

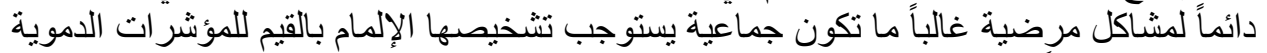

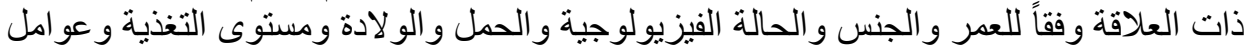

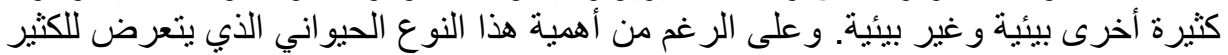

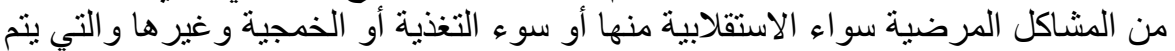

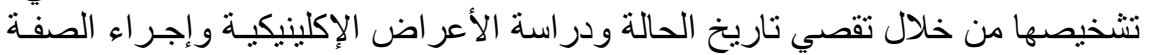

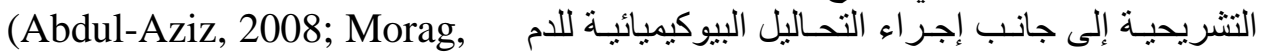

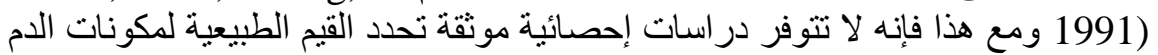

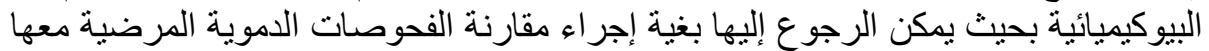

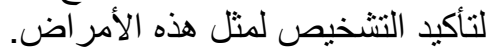

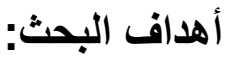

لقد وقع اختيارنا على إجراء هذا البحث من أجل:

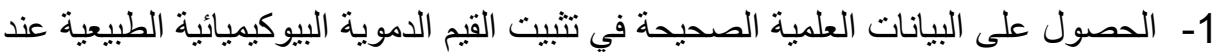

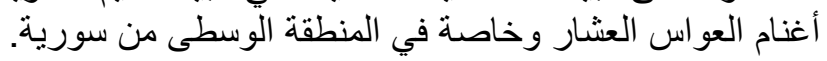

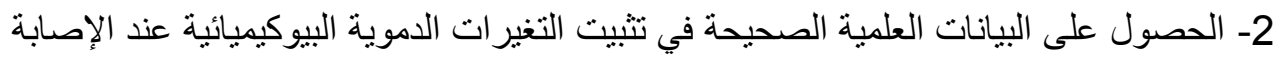
بالتسمح الحملي عند النعاج العثار وخاصة في المنطقة الوسطى من سوريا.

\section{MATERIALS and METHODS} مواد وطرائق البحث

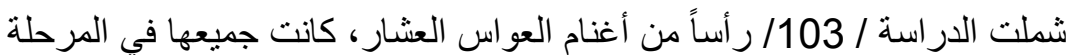

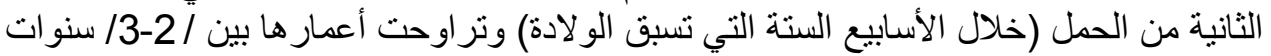

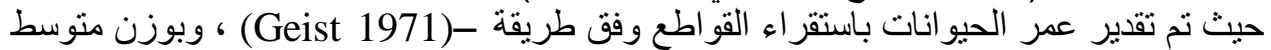

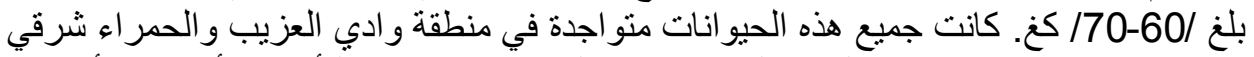

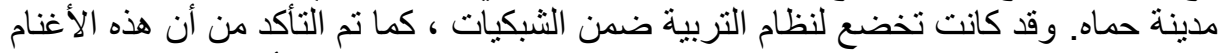

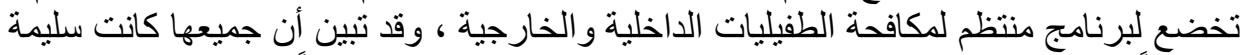

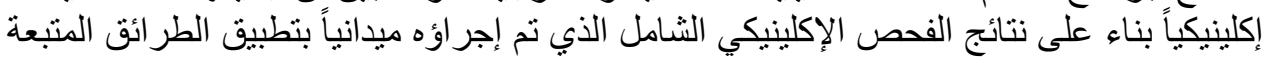


في هذا المجال و الذي من خلاله تم فحص الحر ارة وتقييم ترداد ونظم التنفس و النبض وحالة

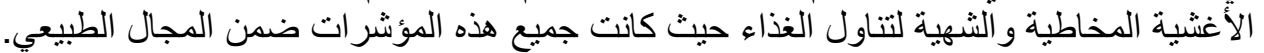

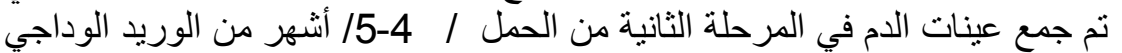

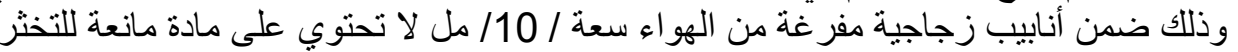
وذللك للحصول على مصل الدام فقط.

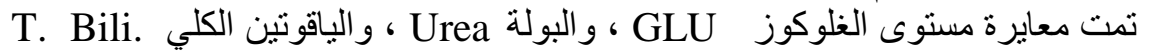

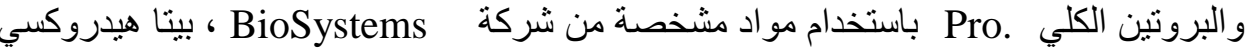

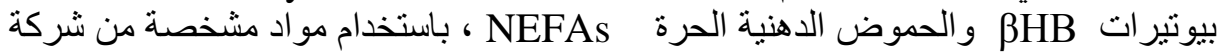

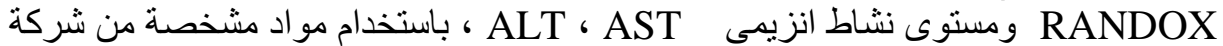

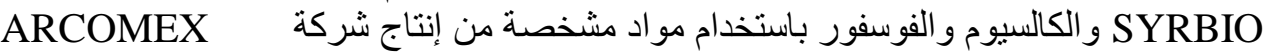

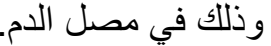
وقد تم إجراء جميع التحاليل السابقة الذكر في مخبر التشخيص المخبري المعهد

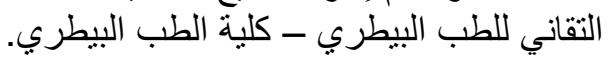

\section{ANALYSIS STATISTICAL التحليل الإحصائي}

تم تدوين النتائج في جداول إلكترونية (EXCELL) ثم نقلت البيانات لتحليلها إحصائياً

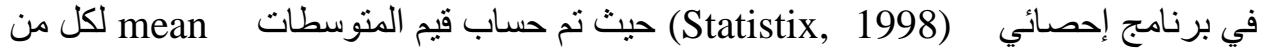

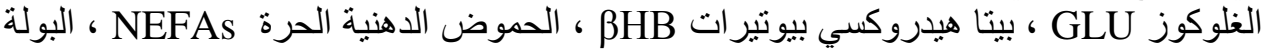
Grea

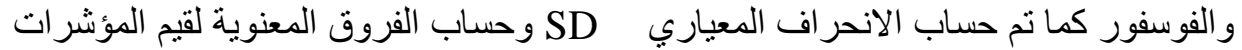
السابقة عند أغنام الثاهد و المصابـة بطريقـة تحليل التباين وحيد الاتجـاه (One-Way AOV).

\section{RESULTS}

\section{النتائسج}

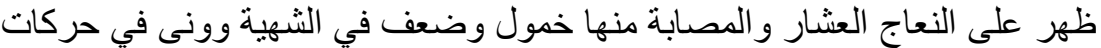

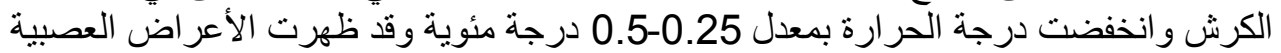

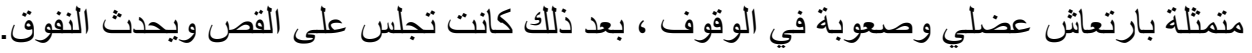

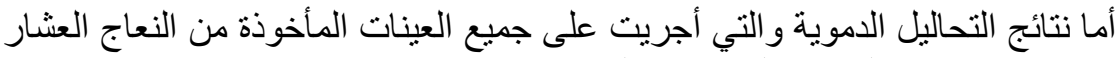

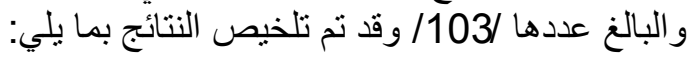

1 - الغلوكوز Glucose) mol/1) : أظهرت المنوسطات الحسابية لقيم الغلوكوز عند النعاج المصابة انخفاضاً و اضحاً حيث بلغت عند الثناهد ويشير ذلك إلى وجود انخفاض معنوي شديد في قيم الغلوكوز بين الثشاهد و المصاب (1)

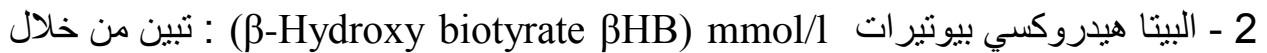
در اسة المنوسطات الحسابية لقيم BHB وجود ارتفاع و واضح في نر اكيز ها حيث بلغت قيمة 


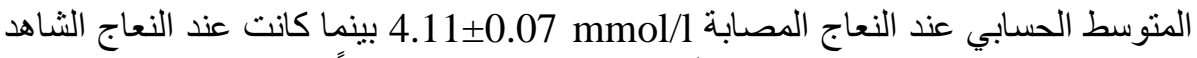

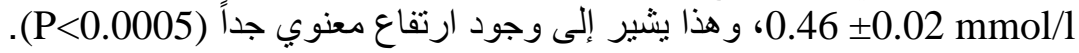

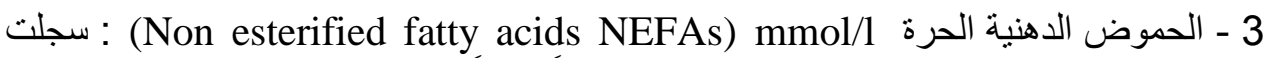

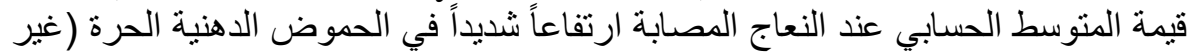
المرتبطة) حيث بلغت mmol/1 ودلت الدراسة الإحصائية لهذه القيم وجود فرق معنوي شديد (P<0.0005). 4 - البولة (Urea) mmol/1) : تشير دراسة النتائج الإحصائية إلى وجود ارتفاع معنوي شديد

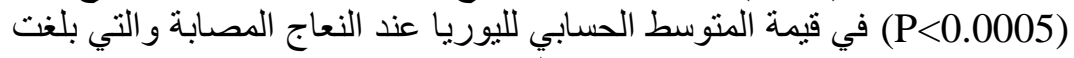

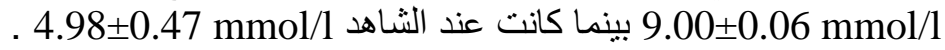

5 - الياقوتين الكلي /Total Bilirubin T. Bili) بmol/1 ) : بلغ المتوسط الحسابي للياقوتين

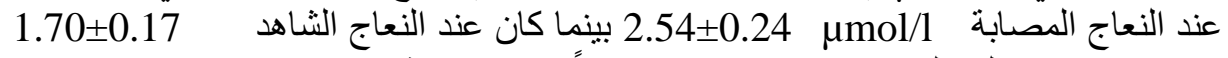

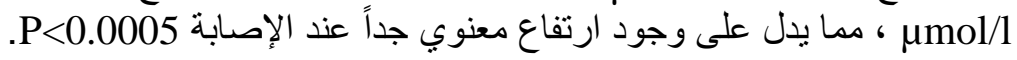

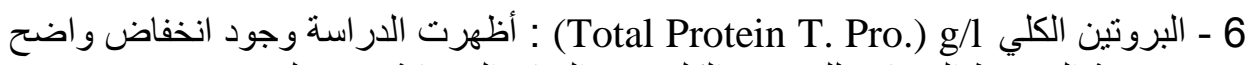

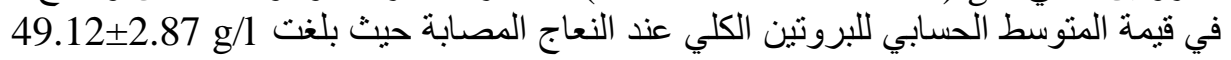
بينما كانت عند النعاج الثاهد معنوي شديد (P<0.0005).

بلغت قيمة : (Aspartate aminotransferase) (AST) U/L (activity level) - 7

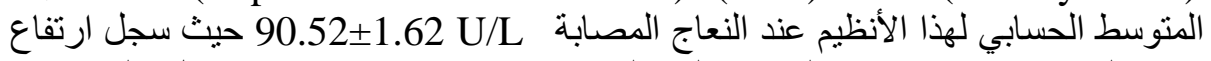

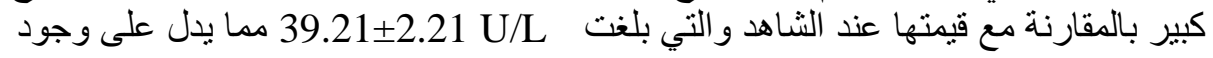
ارتفاع معنوي شديد (P<0.0005).

Alanine aminotransferase(ALT) U/L (activity level) - 8

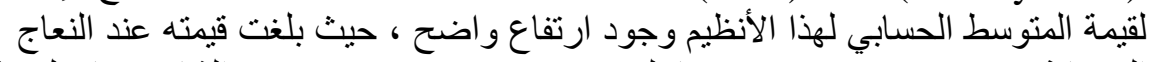

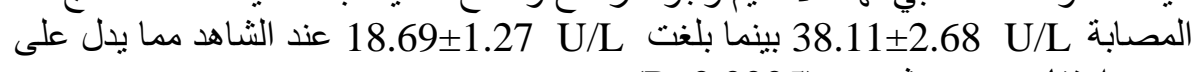
وجود ارتفاع معنوي شديد ، (P<0.0005).

9 - الكالسيوم (Calcium Ca) mmol/1) : تظهر الدراسة عدم وجود فرق معنوي في قيم

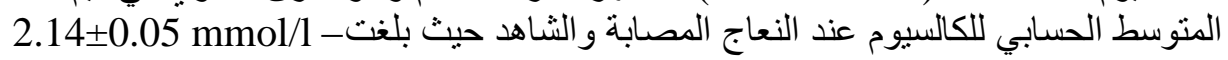

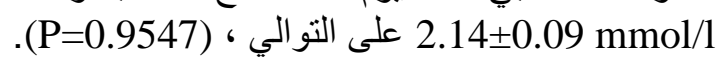

10 - الفوسفور اللاعضوي (Phosphor P.) mmol/1) : بلغت قيمة المتوسط الحسابي للفوسفور

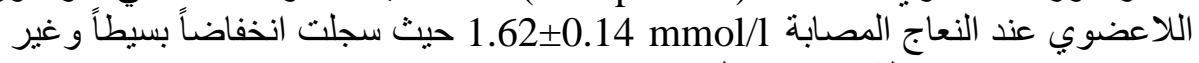

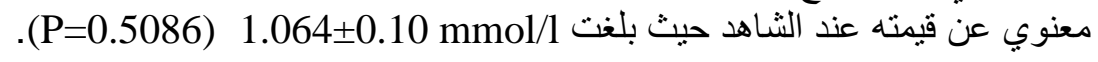

جدول إحصائي رقم 1: يبين نتائج الفحص البيوكيمبائي للام عند النعاج الثاهد

\begin{tabular}{|c|c|c|c|c|c|c|}
\hline القيمة & القيمة & متوسط الخطأ & الفرق & الانحراف & المتوسط & معايير \\
\hline العظمى & الصغرى & المعياري & & المعياري & الحسابي & 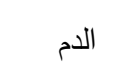 \\
\hline MAX. & MIN. & SE MEAN & VAR. & SD & MEAN & البيوكيميائية \\
\hline
\end{tabular}


Assiut Vet. Med. J. Vol. 56 No. 126 July 2010

\begin{tabular}{|c|c|c|c|c|c|c|}
\hline 2.95 & 2.65 & 0.01 & 0.005 & 0.07 & 2.81 & $\begin{array}{c}\text { Glu. } \\
\mathrm{mmol} / 1\end{array}$ \\
\hline 0.51 & 0.40 & 5.09 & 0.007 & 0.02 & 0.46 & $\begin{array}{c}\beta \mathrm{HB} \\
\mathrm{mmol} / \mathrm{l}\end{array}$ \\
\hline 0.190 & 0.163 & 0.001 & 0.000 & 0.007 & 0.176 & $\begin{array}{c}\mathrm{NEFAs} \\
\mathrm{mmol} / \mathrm{l}\end{array}$ \\
\hline 5.72 & 4.16 & 0.08 & 0.22 & 0.47 & 4.98 & $\begin{array}{c}\text { Urea } \\
\mathrm{mmol} / 1\end{array}$ \\
\hline 1.94 & 1.38 & 0.03 & 0.03 & 0.17 & 1.70 & $\begin{array}{c}\mathrm{T} . \mathrm{Bili} . \\
\mu \mathrm{mol} / \mathrm{l}\end{array}$ \\
\hline 74.70 & 67.94 & 0.31 & 3.01 & 1.73 & 70.90 & $\begin{array}{c}\mathrm{T} . \mathrm{Pro} . \\
\mathrm{g} / \mathrm{l}\end{array}$ \\
\hline 42.68 & 34.92 & 0.40 & 4.88 & 2.21 & 39.21 & $\begin{array}{c}\mathrm{AST} \\
\mathrm{U} / \mathrm{L}(\mathrm{A} . \mathrm{L} .)\end{array}$ \\
\hline 21.30 & 16.20 & 0.23 & 1.63 & 1.27 & 18.69 & $\begin{array}{c}\mathrm{ALT} \\
\mathrm{U} / \mathrm{L}(\mathrm{A} . \mathrm{L} .)\end{array}$ \\
\hline 2.41 & 2.01 & 0.01 & 0.009 & 0.09 & 2.14 & $\begin{array}{c}\mathrm{Ca} \\
\mathrm{mmol} / \mathrm{l}\end{array}$ \\
\hline 1.84 & 1.48 & 0.01 & 0.01 & 0.10 & 1.64 & $\begin{array}{c}\mathrm{P} \\
\mathrm{mmol} / \mathrm{l}\end{array}$ \\
\hline
\end{tabular}


Assiut Vet. Med. J. Vol. 56 No. 126 July 2010

جدول إحصائي رقم 2: يبين نتائج الفحص البيوكيميائي للام عند النعاج المصابة

\begin{tabular}{|c|c|c|c|c|c|c|}
\hline $\begin{array}{l}\text { العظمة } \\
\text { MAX. }\end{array}$ & $\begin{array}{l}\text { الصغيمة } \\
\text { MIN. }\end{array}$ & متوسط الخطأ & الفرق & $\begin{array}{l}\text { الانحراف } \\
\text { SD }\end{array}$ & $\begin{array}{c}\text { المتوسط الحسبي } \\
\text { MEAN }\end{array}$ & البيوكيميائية \\
\hline 1.92 & 1.56 & 0.03 & 0.02 & 0.14 & 1.74 & $\begin{array}{c}\text { Glu. } \\
\mathrm{mmol} / \mathrm{l}\end{array}$ \\
\hline 4.25 & 4.06 & 0.01 & 0.005 & 0.07 & 4.11 & $\begin{array}{c}\beta \mathrm{HB} \\
\mathrm{mmol} / \mathrm{l}\end{array}$ \\
\hline 0.417 & 0.406 & 0.001 & 0.0001 & 0.01 & 0.410 & $\begin{array}{l}\text { NEFAs } \\
\mathrm{mmol} / \mathrm{l}\end{array}$ \\
\hline 9.08 & 8.92 & 0.01 & 0.004 & 0.06 & 9.00 & $\begin{array}{c}\text { Urea } \\
\mathrm{mmol} / \mathrm{l}\end{array}$ \\
\hline 2.84 & 2.18 & 0.05 & 0.06 & 0.24 & 2.54 & $\begin{array}{c}\text { T.Bili. } \\
\mu \mathrm{mol} / \mathrm{l}\end{array}$ \\
\hline 53.23 & 46.59 & 0.59 & 7.75 & 2.87 & 49.12 & $\begin{array}{c}\text { T.Pro. } \\
\text { g/l }\end{array}$ \\
\hline 92.80 & 88.62 & 0.34 & 2.62 & 1.62 & 90.52 & $\begin{array}{c}\text { AST } \\
\text { U/L (A.L.) }\end{array}$ \\
\hline 41.60 & 34.80 & 0.57 & 7.18 & 2.68 & 38.11 & $\begin{array}{c}\text { ALT } \\
\text { U/L (A.L.) }\end{array}$ \\
\hline 2.19 & 2.06 & 0.01 & 0.002 & 0.05 & 2.14 & $\begin{array}{c}\mathrm{Ca} \\
\mathrm{mmol} / 1\end{array}$ \\
\hline 1.84 & 1.48 & 0.03 & 0.02 & 0.14 & 1.62 & $\begin{array}{c}\mathrm{P} \\
\mathrm{mmol} / \mathrm{l}\end{array}$ \\
\hline
\end{tabular}

جدول احصائى رقم 3: يبين المتوسطات الحسابية والانحرافات المعيارية للقيم البيوكيميائية عند نعاج الثاهد والمصابة

\begin{tabular}{|c|c|c|c|c|c|}
\hline المصابة & الثشاهد & القيمة & المصابة & الثناهد & القيمة \\
\hline $\begin{array}{c}2.87 \pm 49.12 \\
* * *\end{array}$ & $1.73 \pm 70.90$ & $\begin{array}{c}\text { T.Pro. } \\
\text { g/l }\end{array}$ & $\begin{array}{c}0.14 \pm 1.74 \\
* * *\end{array}$ & $0.07 \pm 2.81$ & $\begin{array}{c}\text { Glu. } \\
\mathrm{mmol} / \mathrm{l}\end{array}$ \\
\hline $\begin{array}{c}1.62 \pm 90.52 \\
* * *\end{array}$ & $2.21 \pm 39.21$ & $\begin{array}{l}\text { AST } \\
\text { U/L }\end{array}$ & $\begin{array}{c}0.07 \pm 4.11 \\
* * *\end{array}$ & $0.02 \pm 0.46$ & $\begin{array}{c}\beta \mathrm{HB} \\
\mathrm{mmol} / \mathrm{l}\end{array}$ \\
\hline $\begin{array}{c}2.68 \pm 38.11 \\
* * *\end{array}$ & $1.27 \pm 18.69$ & $\begin{array}{l}\text { ALT } \\
\text { U/L }\end{array}$ & $\begin{array}{c}0.01 \pm 0.410 \\
* * *\end{array}$ & $0.007 \pm 0.176$ & $\begin{array}{l}\text { NEFAs } \\
\mathrm{mmol} / \mathrm{l}\end{array}$ \\
\hline $\begin{array}{c}0.05 \pm 2.14 \\
\mathrm{Ns}\end{array}$ & $0.09 \pm 2.14$ & $\begin{array}{c}\mathrm{Ca} \\
\mathrm{Mmol} / 1\end{array}$ & $\begin{array}{c}0.06 \pm 9.00 \\
* * *\end{array}$ & $0.47 \pm 4.98$ & $\begin{array}{c}\text { Urea } \\
\mathrm{mmol} / \mathrm{l}\end{array}$ \\
\hline $\begin{array}{c}0.14 \pm 1.62 \\
\mathrm{Ns}\end{array}$ & $0.10 \pm 1.64$ & $\begin{array}{c}\mathrm{P} \\
\mathrm{Mmol} / \mathrm{l}\end{array}$ & $\begin{array}{c}0.24 \pm 2.54 \\
* * *\end{array}$ & $0.17 \pm 1.70$ & $\begin{array}{l}\text { T.Bili. } \\
\mu \mathrm{mol} / \mathrm{l}\end{array}$ \\
\hline
\end{tabular}


Assiut Vet. Med. J. Vol. 56 No. 126 July 2010

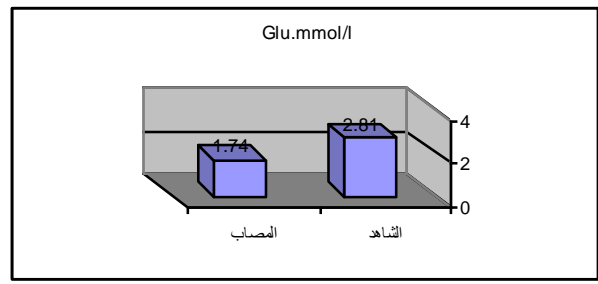

المخطط البياني رقم - 1 - للغلوكوز

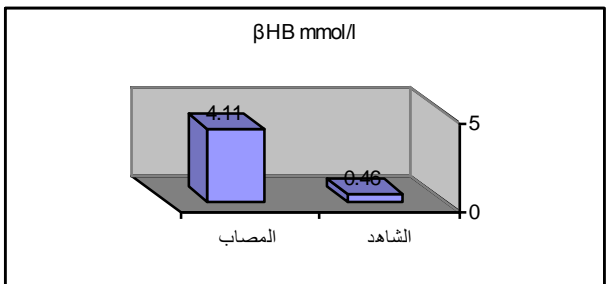

المخطط البياني رقم -2- لبيتا هيدروكسي بيوتيرات

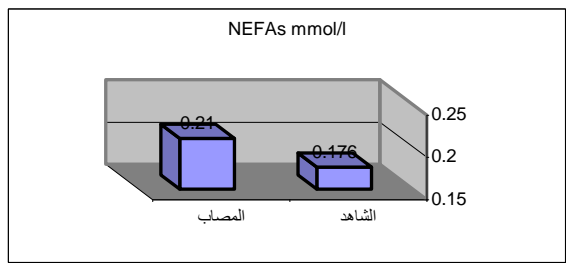

المخطط البياني رقم -3- للحموض الدهنية الحرة

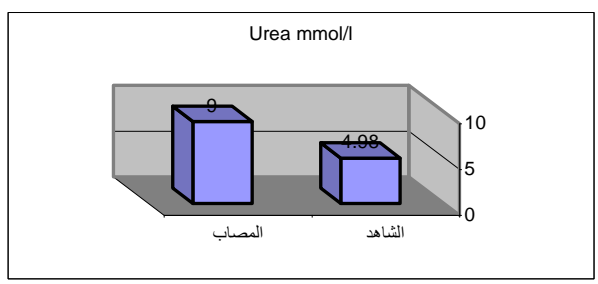

المخطط البياني رقم -4- لليوريا

T.Bili. $\mu \mathrm{mol} / \mathrm{l}$

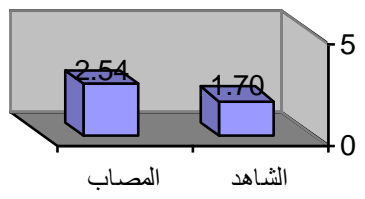

المخطط البياني رقم -5- للياقوتين الكلي 
Assiut Vet. Med. J. Vol. 56 No. 126 July 2010

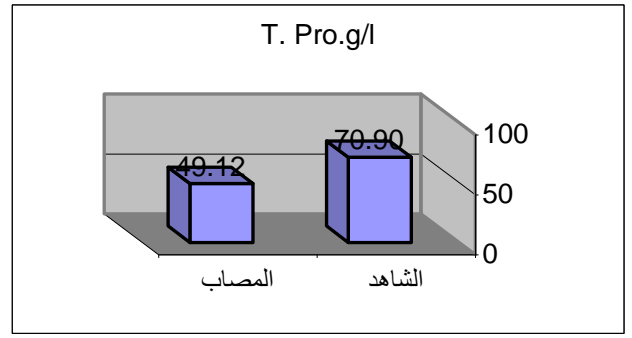

المخطط البياني رقم -6- للبروتين الكلي

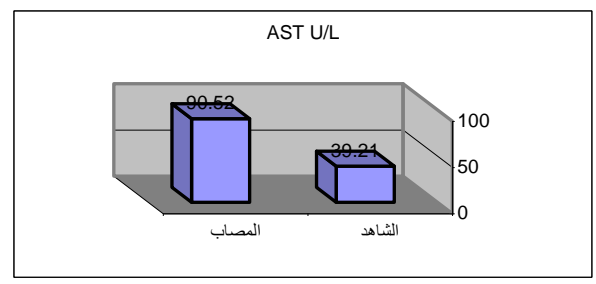

المخطط البياني رقم -7- لمستوى نشاط أنزيم AST

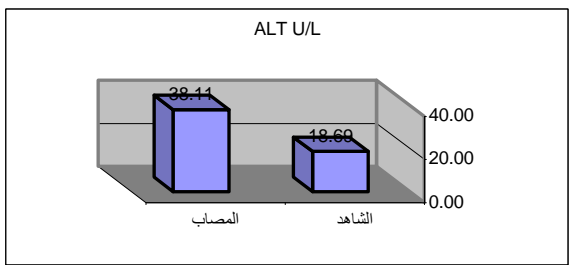

المخطط البياني رقم -8- لمستوى نشاط أنزيم ALT

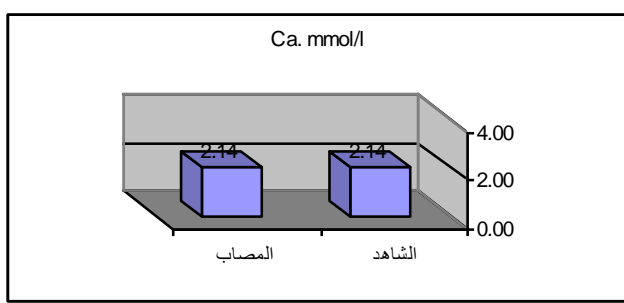

المخطط البياني رقم -9- للكالسيوم

P. $\mathrm{mmol} / \mathrm{l}$

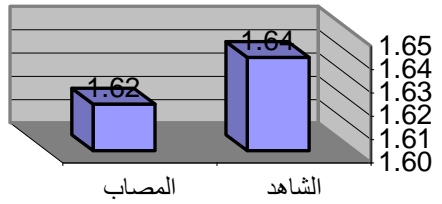

المخطط البياني رقم -10- للفوسفور 


\section{DISCUSSION}

\section{المناقثـة}

تعد معايرة وتحديد تر اكيز مكونات الدم البيوكيميائية الطبيعية وتقييمها عند الأغنام

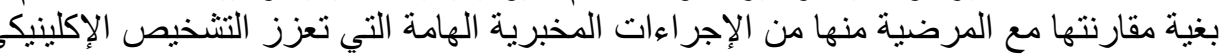

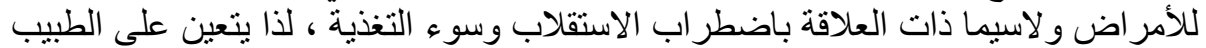

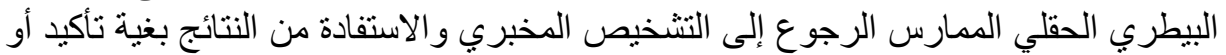

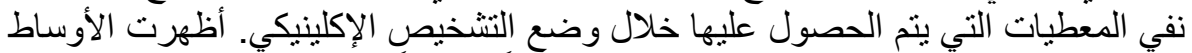

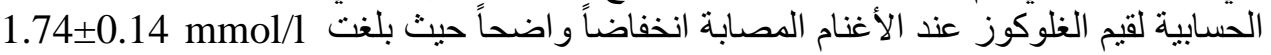

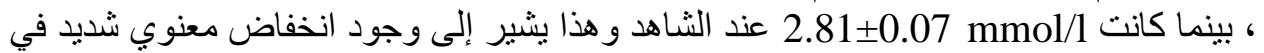

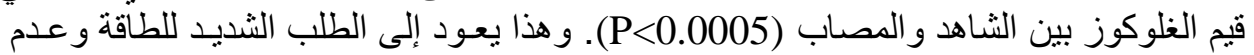

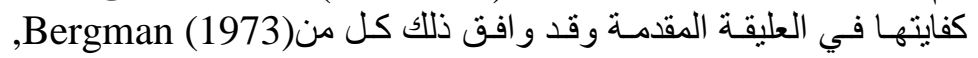

Mehmet and Aysen (2006), Kolb and Kaskous (2004), Kabakci et al. (2003)

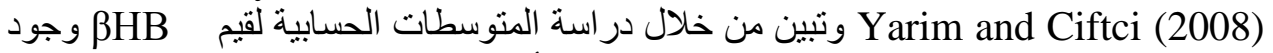

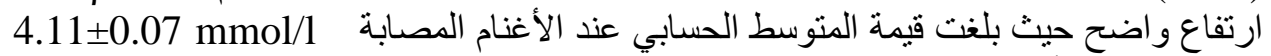

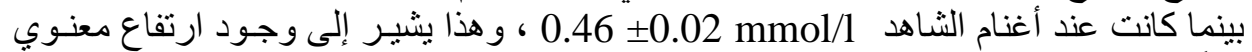

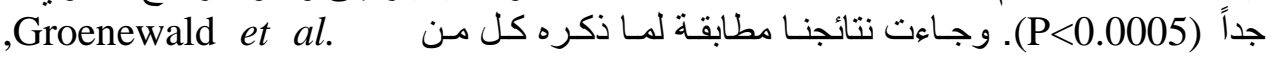
, Henze et al. (1998) Kolb and Kaskous ,El-Sebaie et al. (1992) (1941) (2004)

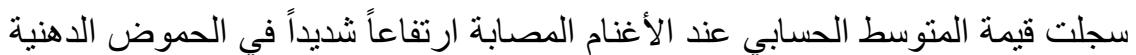

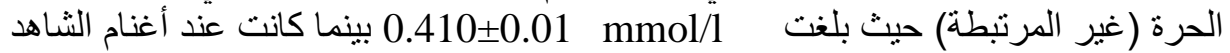

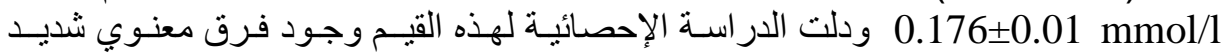

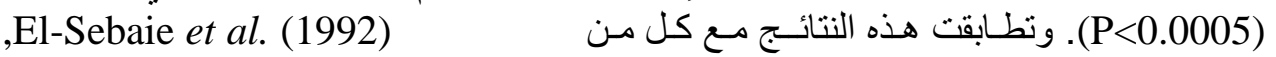
, Kolb and Kaskous (2004) Yarim and Ciftci (2008). ,Bergman (1973) وتثثير دراسة النتائج إلى وجود ارتفاع معنوي شديد (P<0.0005) في قيمة المنوسط

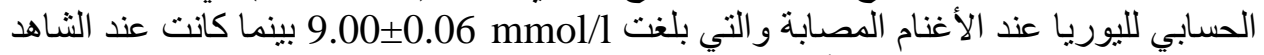

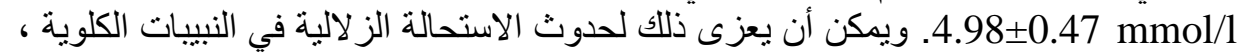

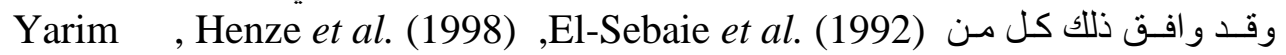
.and Ciftci (2008), Kabakci et al. (2003)

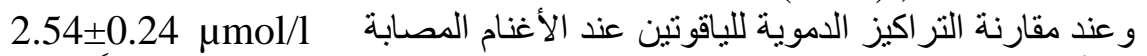

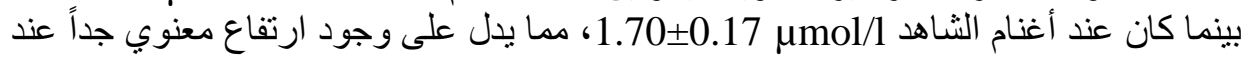

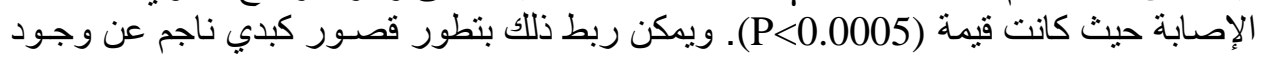

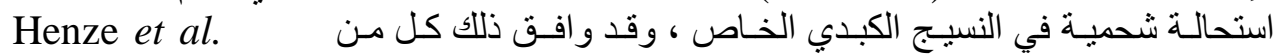
,Kabakci et al. (2003), Mehmet and (1998) ,El-Sebaie et al. (1992)

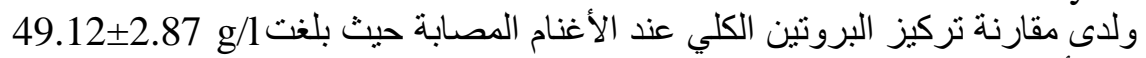
.Aysen (2006)

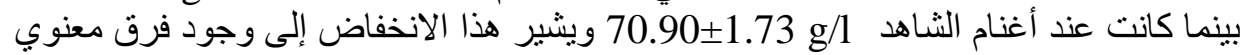

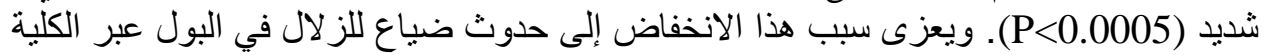

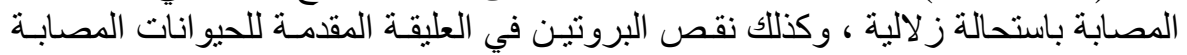




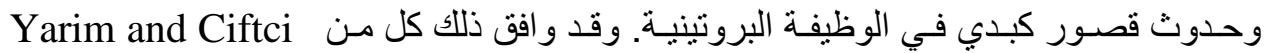
(2008) ,Kabakci et al. (2003), Henze et al. (1998). و أظهرت الدراسة وجود ارتفاع شديد في قيم مستوى نشاط الأنظيمات التي تمت

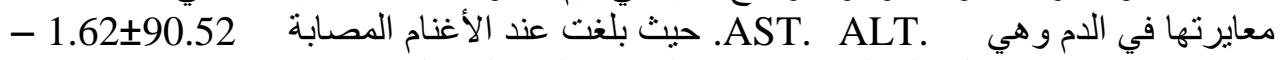

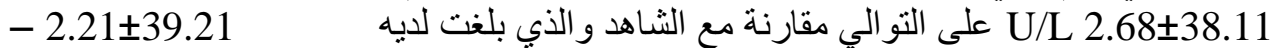

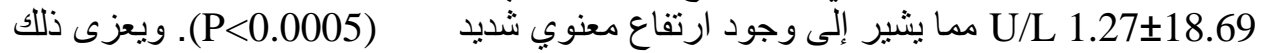
الارتفاع إلى التأذي الحاصل في النسيج الكبدي الخاص و الناجم عن استحالة شحمية فيه وتتنق

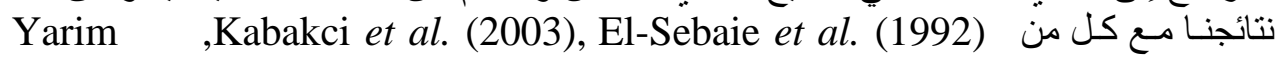
and Ciftci (2008)

أما بالنسبة للكالسيوم و الفوسفور فلم يكن هناك فرق معنوي في قيم الكالسيوم و الفوسفور

عند الأغنام المصابة حيث بلغت

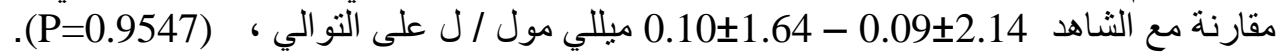

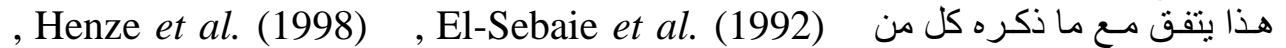
Mehmet and Aysen , Kolb and Kaskous (2004), Kabakci et al. (2003) . (2006)

\section{REFERENCES}

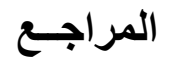

Abdul-Aziz M. Al-Mujalli (2008): Hematological and Biochemical Changes in sheep Associated with Low Dose Freeding of Anagallis Arvensis. Scientific Journal of King Faisal University Vol. 9 No. 11429.

Bergman, E.N. (1973): Glucose metabolism in ruminant as related to hypoglycaemia and ketosis. Am. J. Physiol. 215: 865-873.

Dori L. Borjesson; Mary M. Christopher and Walter M. Boyce (2000): Biochemical and hematologic Reference Intervals for FreeRanging Desert Bighorn Sheep. Journal of Wildlife Diseases, 36(2) pp. 294-300.

El-Sebaie, A.H.; El Shazely, Y.A.; El Gharram, M. and Alhindi, A.B. (1992): Pregnancy toxemia in goets and sheep: clinical updating. Proc. $5^{\text {th }}$. Sci Cong. Vet. Med., Assiut Univ. Nov. 810, 1992, Egypt.

Geist, V. (1971): Mountain sheep, A study in beheviour and evolution university of Chicago press. Chicago, Illinosis, $383 \mathrm{p}$.

Groenewald, J.W.; Graf, H.; Bekker, P.M.; Malan, J.R. and Clark, R. (1941): Domsiekte or Pregnancy disease in sheep I, II. Onderstepoort. Jour. Vet. Sci. and Anim. Indus. 17: 225-296. 
Henze, P.; Bickhardt, K.; Fuhrmann, H. and Sallmann, HP. (1998): Spontaneous pregnancy toxaemia (Ketosis) in sheep and role of insulin. Zentralpl - veterinrmed - A 45 (5) 255-266.

Kabakci, N.; Yarim, G.; Yarim, M.; Duru, O.; Yagci, B. and Kisa, U. (2003): Biochemical investigation of naturally occurring pregnancy toxaemia in sheep pathological, clinical. Acta Veterinaria 53, 2-3: 161-169

Kolb, E. and Kaskous, S. (2004): Patho-biochemical aspects of pregnancy ketosis in sheep and goats. Tier ztliche umschau, 59 7: 374-380.

Mehmet, H.D. and Aysen, A. (2006): Effect of energy deficiency during late pregnancy in chios Ewes free faty acids B-HB and urea metabolites. Turk. J. Vet. Anim. Sci. 30- 497-502.

Morag G. Kerr. (1991): Veterinary laboratory medicine. Clinical Biochemistry and hematology. London.

Statistix (1998): Guiddeline manual analytical softwere, Version 2.0, USA. Yarim, GF and Ciftci, G. (2008): Serum protein pattern ewe pregnancy toxaemia Vet. Res. common. Nov. 25. 